\title{
DE BENTHAM A LE CORBUSIER: VIGILANCIA Y DISCIPLINA EN LA VIVIENDA SOCIAL MODERNA LATINOAMERICANA. EL COMPLEJO HABITACIONAL PEDREGULHO, RÍO DE JANEIRO, BRASIL (1947-1958)
}

\author{
FROM BENTHAM TO LE CORBUSIER: VIGILANCE AND DISCIPLINE \\ IN MODERN LATIN AMERICAN SOCIAL HOUSING. THE PEDREGULHO \\ HOUSING COMPLEX, RÍO DE JANEIRO, BRASIL (1947-1958)
}

\section{PENÉLOPE PLAZA ${ }^{1}$}

\section{RESUMEN}

Este ensayo explora la relación entre las instituciones de poder que encargaron los primeros proyectos de vivienda social moderna en Latinoamérica, su arquitectura y sus habitantes. Como caso de estudio se escoge el Complejo Habitacional Pedregulho construido entre 1947 y 1952, en Brasil. La arquitectura de las nuevas viviendas modernas en Latinoamérica se concibió como el vehículo para la "transformación social". La relación entre la arquitectura, sus ocupantes y el poder se plantea como "panóptica", ya que podemos hallar referencias a formas de "encarcelamiento" propuestas desde la Ilustración estudiadas por el filósofo francés Michel Foucault (como el Panopticon del filósofo inglés Jeremy Bentham), y que hacen eco en las ideas del urbanismo moderno propuestas por el arquitecto y urbanista Le Corbusier.

Palabras clave: Vivienda social, panóptico, modernismo, Foucault, Le Corbusier, Latinoamérica.

\section{ABSTRACT}

This article explores the relationship between the institutions of power that commissioned the first projects of modern social housing in Latin America, its architecture and inhabitants. The Pedregulho Housing Complex is an exemplary case study, built between 1947 and 1952 in Brazil. The new architecture of the modern social housing projects in Latin American was conceived as a vehicle for "social transformation". For this aim, the relationship between power, architecture and tenants is established

${ }^{1}$ Sección de Teoría e Historia de la Arquitectura, Departamento de Diseño, Arquitectura y Artes Plásticas, Universidad Simón Bolívar. Caracas, Venezuela. E-mail: pplaza@usb.ve 
in "panoptic" terms, with clear references to forms of imprisonment proposed since the Enlightenment as studied by the philosopher Michel Foucault (such as Bentham's Panopticon) and that will resonate with Le Corbusier's ideas for the new modern city.

Keywords: Social housing, panopticon, modernism, Foucault, Le Corbusier, Latin America.

Recibido: 13.09.10. Aceptado: 25.06.11.

\section{INTRODUCCIÓN}

$\checkmark$ L PLANEAMIENTO urbano en América Latina desde inicios del siglo XX frecuentemente derivó de la necesidad de erradicar focos de insalubridad que han afectado adversamente la salud de la comunidad (Violich, 1944, p. 47). Para el arquitecto francosuizo Le Corbusier -uno de los pensadores más influyentes de la disciplina urbana de entonces-, la supervivencia de la ciudad moderna radicaba en garantizar la asepsia del nuevo paisaje urbano, lo que a su vez repercutiría en la buena salud de la arquitectura moderna y de sus habitantes:

(...) hay que suprimir el cinturón piojoso de los arrabales, trasladar éstos más lejos y, en su lugar, constituir, poco a poco, una zona de protección libre que, en su día, dará una libertad perfecta de movimientos y permitirá constituir a bajo precio un capital cuyo valor se duplicará y hasta centuplicará (Le Corbusier, 2003, p. 69).

El discurso del Movimiento Moderno, forjado en la Europa de la entreguerra, a favor de una nueva arquitectura para la sociedad moderna y que otorga un rol protagónico a la vivienda social colectiva, tuvo también repercusiones en los grandes proyectos de transformación y modernización de las principales ciudades de América Latina. La vivienda social, según proclamaban los arquitectos modernos, sería el vehículo para modelar una nueva clase obrera higiénica y civilizada, donde la nueva arquitectura se inserta como un instrumento educador para la vida futura en la ciudad del presente. Pero la arquitectura por sí sola no es capaz de re-educar y modificar comportamientos, por lo que será fundamental el papel de la administración pública como ente de poder, responsable de garantizar el orden y la obediencia. Se establece entonces una relación simbiótica de marcado carácter disciplinario entre la arquitectura moderna y las instituciones de poder. La administración pública es la "maquinaria que permite mantener el orden y la disciplina" en los habitantes urbanos, cuyos actos están "re- 
gidos por la anarquía y el individualismo" (Le Corbusier, 2003, p. 10), en especial los pertenecientes a la clase obrera.

Este ensayo explora la relación entre las instituciones de poder que encargaron los primeros proyectos de vivienda social moderna en Latinoamérica, su arquitectura y sus habitantes. Como caso de estudio representativo se escoge el Complejo Habitacional Pedregulho (Fig. 1), construido entre 1947 y 1952 en Río de Janeiro, Brasil. La arquitectura de las nuevas viviendas modernas en Latinoamérica se concibió como el vehículo para

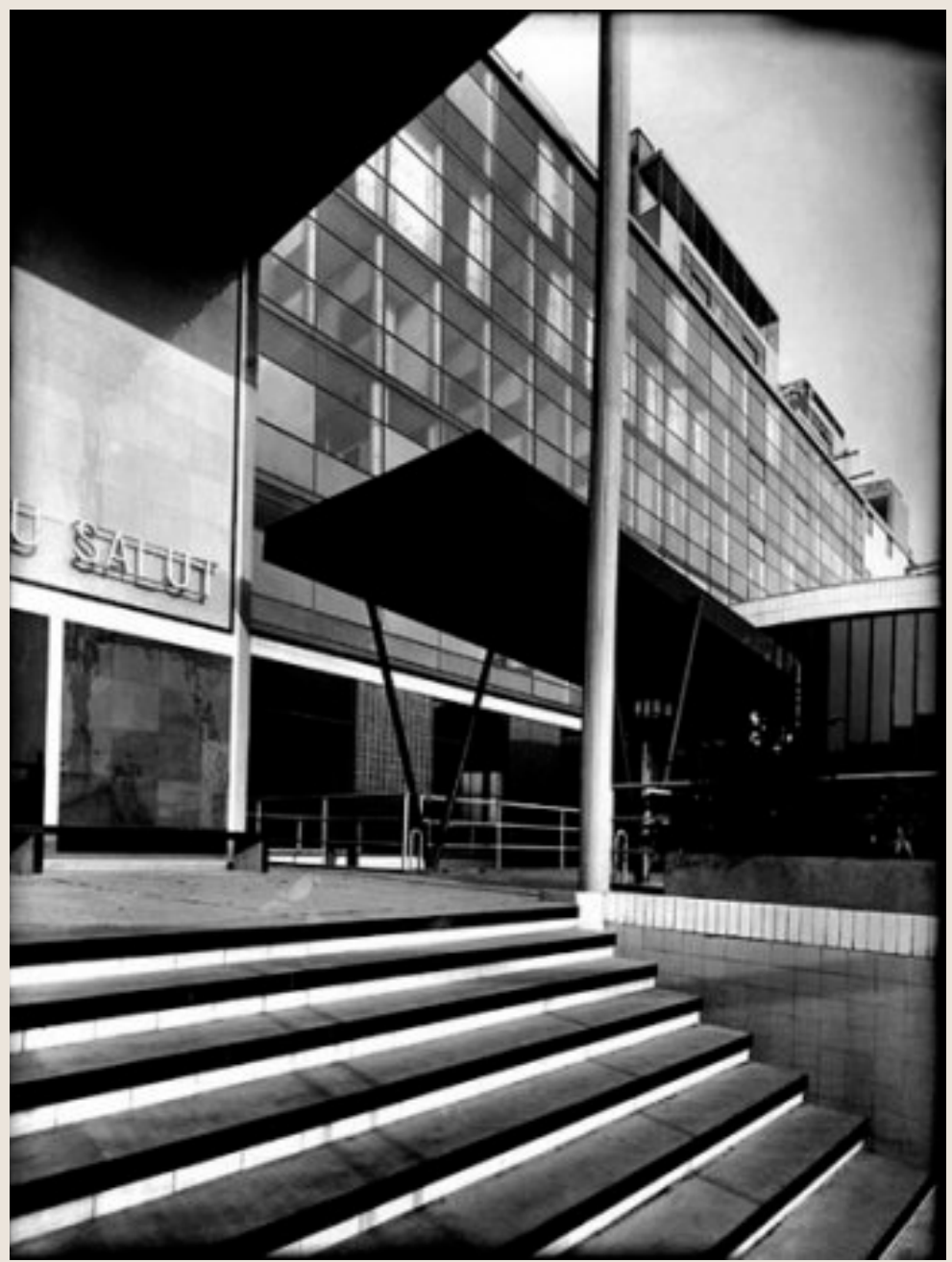

Figura 1. Le Corbusier, ciudad refugio, vista fachada. 
la "transformación social", para la súbita transición de la miseria a la modernidad. La relación entre la arquitectura, sus ocupantes y la autoridad se plantea en este ensayo como "panóptica" ya que, por su carácter disciplinario y la manera como se controlaba el acceso y ocupación a las viviendas modernas, podemos hallar referencias a formas de "encarcelamiento" propuestas desde la Ilustración estudiadas por el filósofo francés Michel Foucault, en especial el Panopticon del filósofo inglés Jeremy Bentham, y que hacen eco en las ideas de arquitectura y urbanismo modernos propuestas por Le Corbusier.

\section{VIVIENDA MODERNA Y CONTROL SOCIAL: LE CORBUSIER Y LA CIUDAD REFUGIO DEL EJÉRCITO DE SALVACIÓN, PARÍS, 1928-1933}

En los años posteriores a la Primera Guerra Mundial, el gobierno francés, a diferencia de países como Alemania o Inglaterra, no desarrolló un programa consistente de planificación y construcción de viviendas. Tampoco mostró mucho interés en incorporar las propuestas sobre vivienda social de los arquitectos modernos (Von Moos, 2009, p. 147). Arquitectos como Le Corbusier concentraron entonces sus esfuerzos en captar la atención de la élite cultural e industrial y entes privados que estuvieran dispuestos a financiar la construcción de nuevos tipos de vivienda social. Es en este contexto que surge la estrecha colaboración entre el Ejército de Salvación de Francia y Le Corbusier.

La construcción de una extensión para el Palais du Peuple entre 1926 y 1927 inaugura la fructífera relación de Le Corbusier con el Ejército de Salvación. Para la organización benéfica, la vivienda podía funcionar como instrumento "de rescate social con benevolencia cristiana"; revelando una afinidad con las ideas de reforma social de Le Corbusier (Von Moos, 2009, p. 152). Posteriormente, Albin Peyron, el comandante del Ejército de Salvación en Francia, tuvo la visión de crear un hospicio con servicios colectivos médicos y legales para atender a los más desfavorecidos. Este hospicio se construye finalmente entre 1928 y 1933, denominado Cité du Refuge (Ciudad Refugio) diseñado también por Le Corbusier. El edificio era entendido como una gran "fábrica del bienestar" (Von Moos, 2009, p. 152) o bien una máquina para domesticar.

La fe en la tecnología y la máquina como instrumentos para la reforma social encuentra parte de sus fundamentos en el Taylorismo, método de disciplina y organización laboral basado en investigaciones científicas sobre 
eficiencia y sistemas de incentivos, ideado por el norteamericano Frederick W. Taylor, y popularizado en los primeros años del siglo XX (Mc Leod, 1983, p. 133). El Taylorismo implicó, según sus propios seguidores, un cambio revolucionario en el esquema mental del mundo laboral, que permeó hacia otras esferas del conocimiento, como la arquitectura y el urbanismo. El Taylorismo cautivó especialmente a los arquitectos modernos europeos, de Alemania, Italia, la Unión Soviética y Francia. Como disciplina la arquitectura fue la más receptiva a los nuevos métodos e ideas provenientes del mundo industrial; los arquitectos modernos produjeron un acompañamiento edificado y estético de la ideología técnica y científica del Taylorismo. Viviendas, edificios públicos, fábricas y demás artefactos emergieron como la síntesis de la belleza, la tecnología y la eficiencia económica y social (Guillén, 1997, p. 683).

Hacia la década de los '20 para Le Corbusier, el Taylorismo y la producción en serie, pasaron a ser elementos fundamentales para la renovación social. Si bien sus principios formales estaban inspirados en la estética de la máquina, la promesa de la eficiencia industrial le permitió concebir a la arquitectura como una herramienta social (Mc Leod, 1983, p. 135). Le Corbusier se alineó con el pensamiento de la Redressement Francais precisamente al momento en que estaba diseñando la Ciudad Refugio. Impresionados por el Taylorismo, los miembros de la Redressement Francaise creían que los conflictos sociales podían evitarse y que el progreso económico podía lograrse a través de la reforma social. Creían fervientemente que para materializar una revolución social, pacífica, la clase trabajadora necesitaba de una férrea disciplina impuesta desde arriba por una élite de expertos (Brace Taylor, 1979, pp. 183-184). Le Corbusier creía que el arquitecto, en colaboración con otros especialistas, debía buscar el conocimiento científico que le condujera al mejoramiento de las condiciones fisiológicas del habitar humano, y que el bienestar espiritual o psicológico ocurriría como consecuencia de la adaptación del individuo al entorno tecnológico moderno (Brace Taylor, 1979, p. 179). El arquitecto moderno, entonces a través de sus edificaciones, pasaría a ser un agente del nuevo orden social.

Ubicada sobre la Rue Cantagruel en París, la Ciudad Refugio consta de un gran bloque, construido en hormigón armado con fachada hermética (Fig. 1) de curtain wall -en décadas posteriores el curtain wall fue sustituido por ventanas precedidas por brise soleils multicolores (Fig. 2); el acceso desde la calle es marcado por un gran atrio cúbico abierto que conduce a una rotonda donde se ubica la recepción de los servicios sociales del Ejército de Salvación (Fig. 3). La Ciudad Refugio fue concebida para alojar 


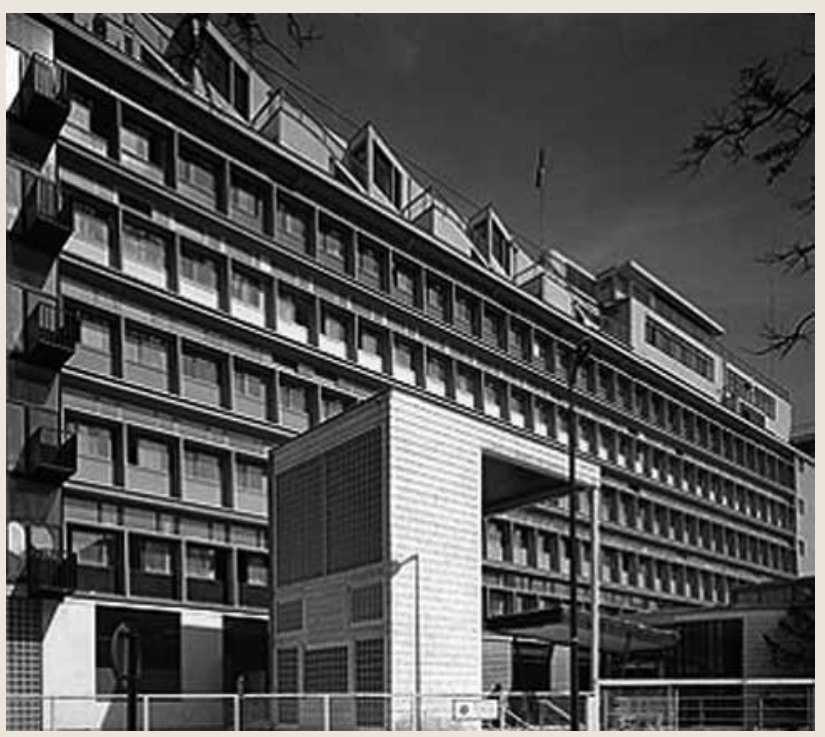

Figura 2. Le Corbusier, Ciudad Refugio, vista actual.

pordioseros, vagabundos, ex-convictos, madres solteras y desempleados, siendo receptáculo y depósito de individuos “indeseables" que debían ser regenerados.

Las ambiciones de una organización de beneficencia social como el Ejército de Salvación, son elementos claves a tomar en cuenta para una comprensión de la configuración espacial del edificio, la relación con sus ocupantes y la manera como fue regentado por las autoridades. Los espacios de la edificación fueron diseñados para acomodar el proceso de transformación social al que sería sometido todo aquel que ingresaba al recinto. Todas las actividades a las que eran sometidos los habitantes de Ciudad Refugio estaban rígidamente planificadas, en espacios específicos, a horas específicas. Algunas actividades, como comer, eran reguladas por campanas que sonaban a lo largo de todo el edificio (Brace Taylor, 1979, p. 183). La rehabilitación del desviado radicaba, según el Ejército de Salvación, en la conversión religiosa y la sumisión a la férrea disciplina del trabajo diario.

En su concepción, la Ciudad Refugio mantiene un cercano parentesco con instituciones de reforma penal, aunque se sitúa en un punto medio entre el encarcelamiento y la libertad de movimiento (Brace Taylor, 1979, p. 182). El atributo clave que las instituciones de confinamiento y reforma social tienen en común es el aislamiento. La Ciudad Refugio es hermética, 


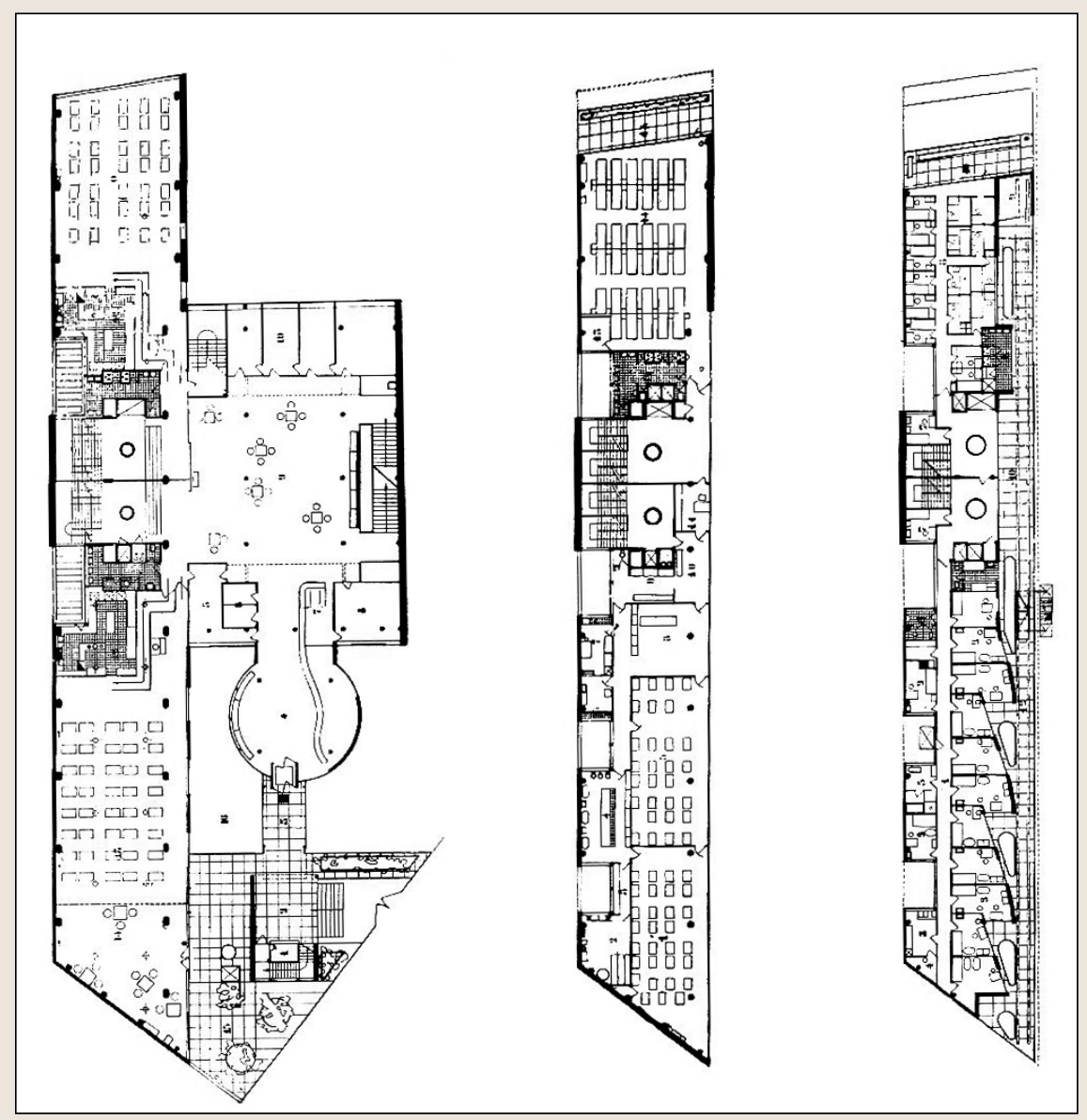

Figura 3. Le Corbusier, Ciudad Refugio, plantas.

aísla todo contacto con el exterior a través de sus mil metros cuadrados de fachada-vidriera. Los espacios internos de la edificación, fiel expresión de los espacios creados por la modernidad, con sus interiores desprovistos de decoración y el ubicuo cristal en sus cerramientos, pueden ser considerados también elementos "panópticos", que crean espacios con una gran visibilidad, crucial para una efectiva vigilancia. Son éstos espacios entregados a la visión: la visibilidad total del espacio y de cualquier cosa o elemento que lo ocupe. En este sentido, el cuerpo de habitaciones de la Ciudad Refugio puede ser considerado entonces como un contenedor "panóptico". Efectivo en el aislamiento de sus habitantes, el cuerpo acristalado de las habitaciones 
clausura el contacto con el exterior, cual si fuera una gran incubadora urbana donde se gesta el proceso de transformación del individuo "indeseable" en un individuo útil y aceptable para la sociedad moderna.

Le Corbusier expandió los confines de este control espacial y disciplinario hacia un control total sobre el cuerpo humano a través de sofisticados mecanismos de control climático. La rígida disciplina colectiva impuesta por el Ejército de Salvación en el uso de los espacios y el comportamiento social fue llevada a un grado superior, ejerciendo un control extendido hacia el cuerpo en un ambiente artificialmente controlado y mecanizado. Arquitectura y reforma social funcionan entonces de manera simbiótica, encarnando el instrumento perfecto para lograr la transformación social a la que aspiraba el Ejército de Salvación (Brace Taylor, 1979, p. 183).

\section{VIVIENDA Y SEGURIDAD SOCIAL EN RÍO DE JANEIRO}

Los planes urbanos desarrollados en América Latina entre las décadas de 1900 y 1930 carecieron de propuestas de desarrollos habitacionales y de servicios para la clase trabajadora, en especial en las ciudades que crecían rápidamente (Morse y Hardoy, 1992). La mayoría de la población urbana de las principales ciudades latinoamericanas ocupaba viviendas precarias. En su libro Cities of Latin America, el urbanista norteamericano Francis Violich (1944, p. 61) observa que para 1944 sólo un tercio de la población del continente habitaba viviendas apropiadas; con lo que se estima que las dos terceras partes de la población ocupaban viviendas precarias, con una calidad de vida igualmente precaria.

En el transcurso de la primera mitad del siglo XX y especialmente durante los años 40, la mayoría de los países de Latinoamérica se embarcaron en procesos de industrialización y crecimiento económico, acelerando el crecimiento físico y demográfico de sus principales ciudades. Como Violich afirma en sus observaciones, la provisión de vivienda para los sectores más pobres de la población urbana era un problema que los gobiernos debían solucionar con urgencia. Esta observación es confirmada por Morse y Hardoy (1992, p. 47), quienes señalan que, hasta la década de 1930, "la clase trabajadora, mal pagada o desempleada, tuvo que buscar sus propias soluciones a problemas básicos de supervivencia", recurriendo a pensiones sobrepobladas, la compra de lotes subdivididos de forma ilegal o la invasión de tierras.

Llegada la década de los 40, los gobiernos latinoamericanos comenzaron 
a invertir en la construcción de viviendas, haciendo uso de fondos de seguridad social para desarrollos de programas habitacionales (Morse y Hardoy, 1992, p. 46). Desde sus inicios, la seguridad social en Latinoamérica no sólo estuvo orientada a asegurar fondos para la vejez, sino también seguridad de salud, servicio médico gratuito, seguro de vida, préstamos para la construcción y la provisión de viviendas. Sin embargo, la desigualdad en la distribución de los ingresos determinaba que sólo un pequeño porcentaje de la población tenía acceso al mercado inmobiliario.

En Brasil no se había demostrado un serio interés en solucionar los problemas de vivienda creados por la rápida expansión de la población urbana (Fraser, 2000, p. 190). El desalojo forzado de emplazamientos ilegales en Río se enfrentó a una fuerte resistencia. El programa de seguridad social y construcción de viviendas tuvo su implementación más amplia en Brasil en la década de los cuarenta, contando con un gran impulso gracias a las favorables condiciones económicas de la administración de Getulio Vargas. Los fondos de seguridad social financiaron la construcción de todas las viviendas de bajo costo. Sin embargo, no existía un organismo que formulara políticas de vivienda para ser instrumentadas a nivel nacional.

La planificación urbana llevada a cabo en ciudades como Río de Janeiro, Sao Paulo, Belo Horizonte y otras, fueron el resultado de iniciativas de personalidades locales y oficinas de planificación privadas (Violich, 1944, p. 95). Los más importantes proyectos de reordenamiento urbano se llevaron a cabo en Río de Janeiro, la capital del país hasta 1961, cuando se traslada a la nueva ciudad de Brasilia. Río contaba con una comisión de planificación, la Comisão do Plano da Cidade, creada en 1937. Su personal estaba compuesto por funcionarios y técnicos designados por el alcalde, quien a su vez era designado por el Presidente. Esta comisión tenía la desventaja de ser manejada políticamente, excluyendo la participación de representantes de la población (Violich, 1944, p. 95).

Se estimaba que cerca de un 75 por ciento de la población de Río de Janeiro vivía en casas precarias; las zonas más acomodadas de la ciudad como Copacabana, Ipanema, Tujica entre otras no albergaban a más de 600.000 personas en modernas residencias, mientras que los 2.000 .000 restantes habitaban viviendas deterioradas por el uso intensivo (Violich, 1944, p. 76). El habitante promedio de Río de Janeiro destinaba la mitad de sus ingresos al pago de alquiler.

Los gobiernos de izquierda del período de postguerra en Brasil (19451964) fomentaron la experimentación arquitectónica como parte de un amplio programa de reformas políticas. Brasil ya había fijado su lugar en la 
historia de la arquitectura moderna con el Ministério da Educação e Saúde (Ministerio de Educación y Salud) en Río de Janeiro, diseñado por un grupo de jóvenes arquitectos (Lucio Costa, Oscar Niemeyer, Affonso Eduardo Reidy, entre otros) con la asesoría de Le Corbusier, construido entre 1937 y 1942 (Fig. 4). Le Corbusier realizó su primera visita a Río en 1929, como parte de su gira por América del Sur, "enamorándose" de la ciudad (Evenson, 1973). Creó un plan maestro, derivado de su propuesta para la Ville Contemporaine de 1922, consistente en una autopista costera elevada sobre la ciudad y bajo la superficie de la autopista, quince pisos de residencias (Fig. 5).

Le Corbusier visitó Río por segunda vez en 1936 por invitación del Ministerio de Educación y Salud, quien lo requirió como asesor para el diseño de la nueva sede del ministerio y la creación de un nuevo complejo universitario para la ciudad. Además de trabajar con los jóvenes arquitectos bra-

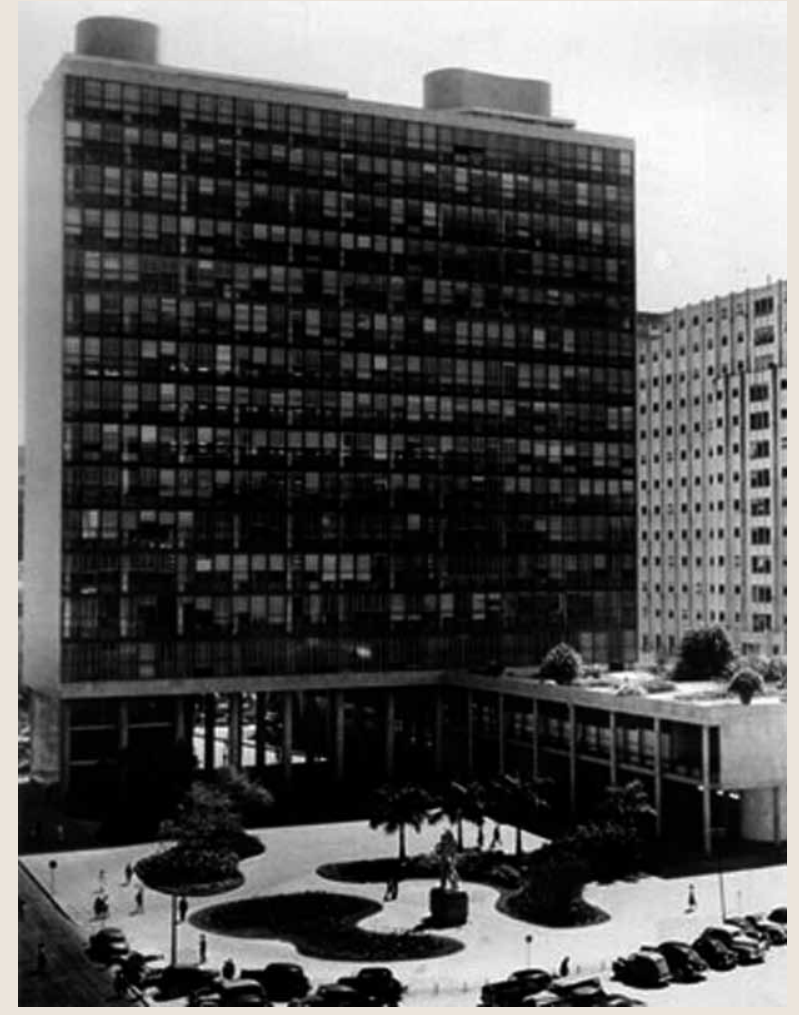

Figura 4. Ministerio de Educación y Salud, fachada (Archivo Gustavo Capanema, CODOC FGV vitruvius.com.br). 


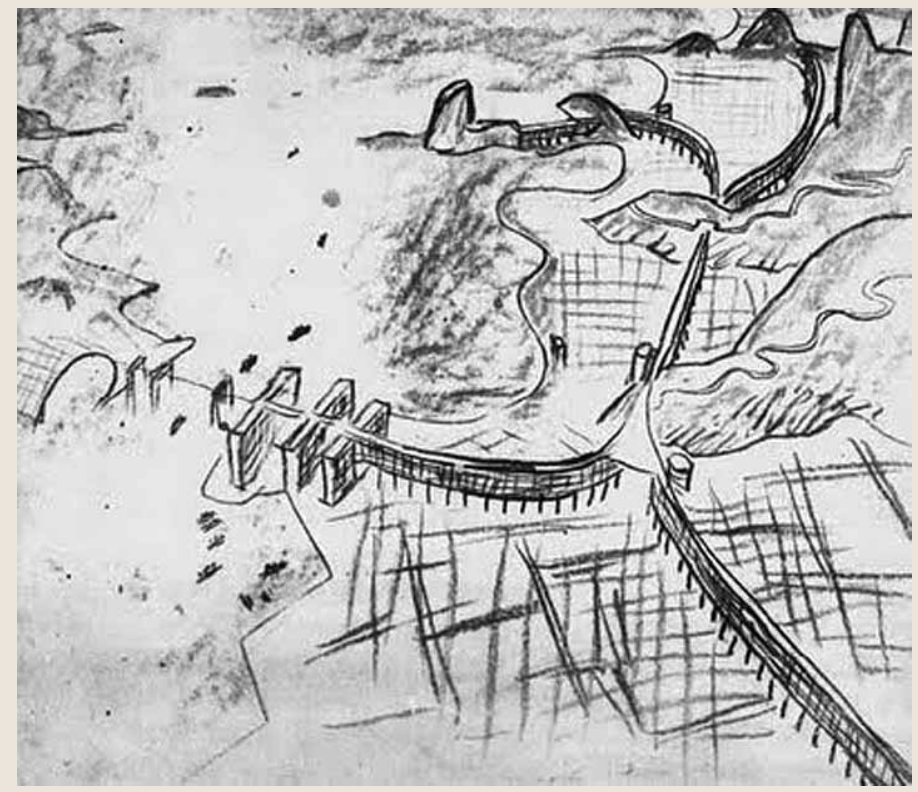

Figura 5. Estudio urbanización Río de Janeiro, vista aérea. Le Corbusier.

sileños involucrados en el proyecto, Le Corbusier dictó una serie de conferencias públicas sobre arquitectura y urbanismo. Su estadía en Río fue muy valiosa y marcaría la arquitectura en Brasil por décadas (Evenson, 1973).

Una vez finalizada la sede del Ministerio de Educación y Salud se envió como delegada a París a Carmen Portinho (1903-2001), una de las figuras locales más influyentes en la cultura moderna brasileña, para reunirse con Le Corbusier y mostrarle las fotografías del edificio. Portinho fue la tercera mujer en Brasil en graduarse como ingeniero civil en 1926 de la Escuela Politécnica de la Universidad de Brasil (actual Universidad Federal de Río de Janeiro), y la primera mujer en recibir el título de urbanista por parte de la extinta Universidad del Distrito Federal. Fue miembro de la Federação Brasileira pelo Progresso Femenino (Federación Brasileña para el Progreso Femenino), con quienes logró persuadir a Getulio Vargas para conceder el voto femenino en 1932. En 1944 se le otorga una beca para estudiar los desarrollos de vivienda social en Inglaterra y a su regreso a Brasil en 1947, funda y dirige el Departamento de Vivienda Popular en Río de Janeiro, nombrando como arquitecto en jefe del Departamento a su compañero sentimental, Affonso Reidy. Ese mismo año propone la construcción del Complejo Habitacional Pedregulho, diseñado por el mismo Reidy. 


\section{UN NUEVO MODELO DE VIVIENDA SOCIAL: EL COMPLEJO HABITACIONAL PEDREGULHO}

Las iniciativas de vivienda social como Pedregulho, ejecutadas en la década de los cuarenta en Brasil, tienen en común un factor clave: ser símbolos de una promesa de progreso, de la expectativa de que la arquitectura sería un vehículo de transformación social a través de la "domesticación" de los escogidos para ocupar los nuevos apartamentos; la solución que pondría fin a las favelas y las viviendas precarias. Pedregulho se planteó como un nuevo modelo de vivienda en Brasil, accesible para aquellos trabajadores cuyos salarios no fueran lo suficientemente altos para comprar o alquilar un apartamento en la ciudad. La propuesta tiene claras referencias a las ideas y proyectos de Le Corbusier, así como a los preceptos de los CIAM sobre desarrollos urbanos de alta densidad.

Desde un principio, los CIAM (Congresos Internacionales de Arquitectura Moderna) fueron concebidos como un instrumento de propaganda para avanzar la causa de la nueva arquitectura que se estaba desarrollando en Europa durante la década de 1920; el grupo jugó un papel clave en la creación de un sentido unificado de "lo que ahora se conoce como El Movimiento Moderno" (Mumford, 2000, p. 1). Desde 1933 hasta 1947, CIAM estuvo dominado por el propio Le Corbusier, quien cambió el enfoque hacia el planeamiento urbano (Frampton, 1994, p. 270). La nueva arquitectura "funcional" y "racional" necesitaba de un cambio en la manera de planificar las ciudades. El CIAM IV, conocido como "El Congreso de la Ciudad Funcional" tuvo lugar en el verano de 1933 a bordo del barco S.S. Patris II, viajando de Atenas a Marsella. Los resultados de este congreso fueron la base de lo que Le Corbusier llamó "La Carta de Atenas", publicada en 1943. Las ciento once proposiciones que comprenden la Carta consistían en parte de planteamientos sobre las condiciones de las ciudades, y en parte de propuestas para la rectificación de esas condiciones agrupadas dentro de cinco preceptos: Vivienda, Ocio, Trabajo, Transporte y Edificios Históricos (Frampton, 1994, p. 270). Pedregulho aplica estas estrategias dentro de la organización del conjunto arquitectónico, aplicando tres de los cinco preceptos: Vivienda, Ocio y Transporte.

Affonso Reidy ya contaba con experiencia previa en el desarrollo de proyectos de vivienda social moderna, habiendo diseñado y construido, en 1930, un Refugio para Indigentes en Río de Janeiro. Durante el proceso de diseño de Pedregulho, Reidy y su equipo se entrevistaron con los futuros 
inquilinos; en las conversaciones se discutieron los servicios comunes que debería contener el complejo (escuela, parques, etc.) y se realizó un censo. El proyecto debía alojar a 478 familias en apartamentos de dos a cuatro habitaciones comprendidos en cuatro bloques cubriendo un área de 50.000 $\mathrm{m}^{2}$, así como una escuela básica, gimnasio, una piscina olímpica con vestidores, un centro de salud, parques, una guardería y una lavandería comunal (Fig. 6). Esta mezcla de amenidades sociales fueron distribuidas en cuatro volúmenes independientes. El volumen más prominente, con 272 apartamentos, es un sinuoso paralelepípedo de 260 metros de largo y siete pisos de alto que se elevan en pilotis sobre la colina dominando el conjunto. Se encuentra dividido en dos secciones horizontales por una planta libre intermedia, donde ocurre el acceso y está destinado a la recreación bajo techo (Figs. 7 y 8). En la sección superior del bloque se distribuyen unidades de vivienda dúplex y en la sección inferior unidades de vivienda para solteros. Henrique Mindlin, en su libro Modern Architecture in Brazil (Fraser, 2000, p. 193) emparenta estéticamente este sinuoso edificio con las propuestas de Le Corbusier para un desarrollo habitacional en Argelia y la propuesta de la curvilínea autopista residencial para Río de Janeiro propuesta en 1929. Los dos bloques de apartamentos adicionales, ambos de 80 metros de largo, también conteniendo unidades de vivienda dúplex, están ubicados en las

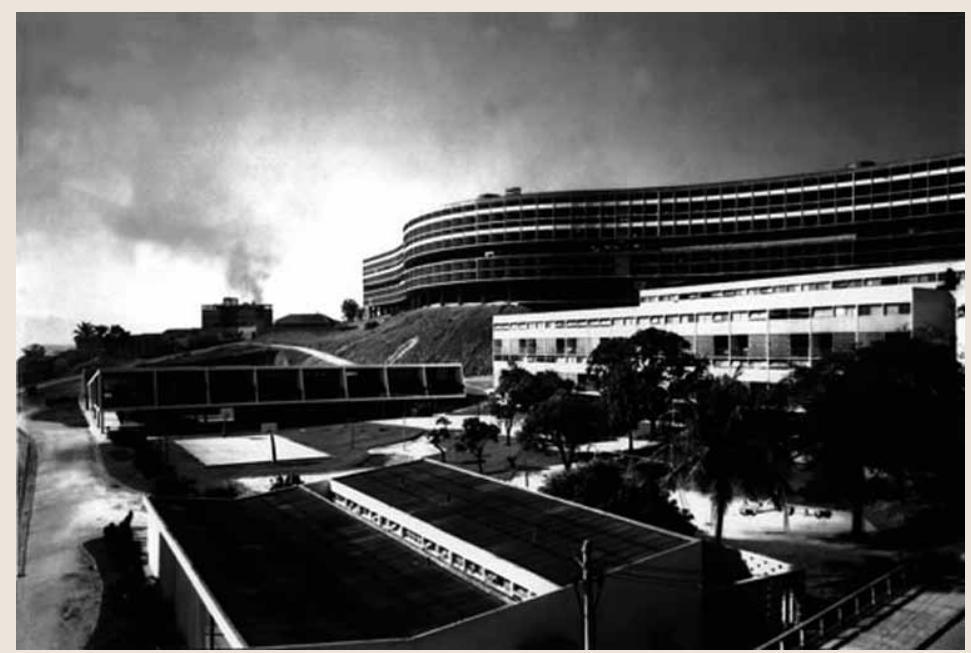

Figura 6. Affonso Eduardo Reidy Pedregulho, c. 1960 (Foto de Marcel Gautherot). 


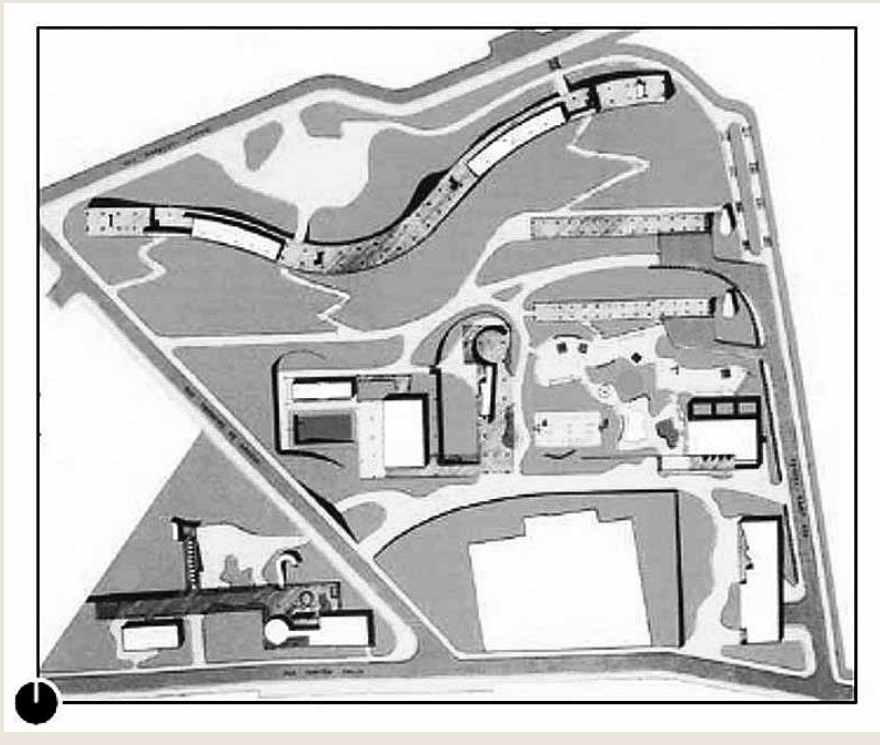

Figura 7. Pedregulho, planta conjunto.

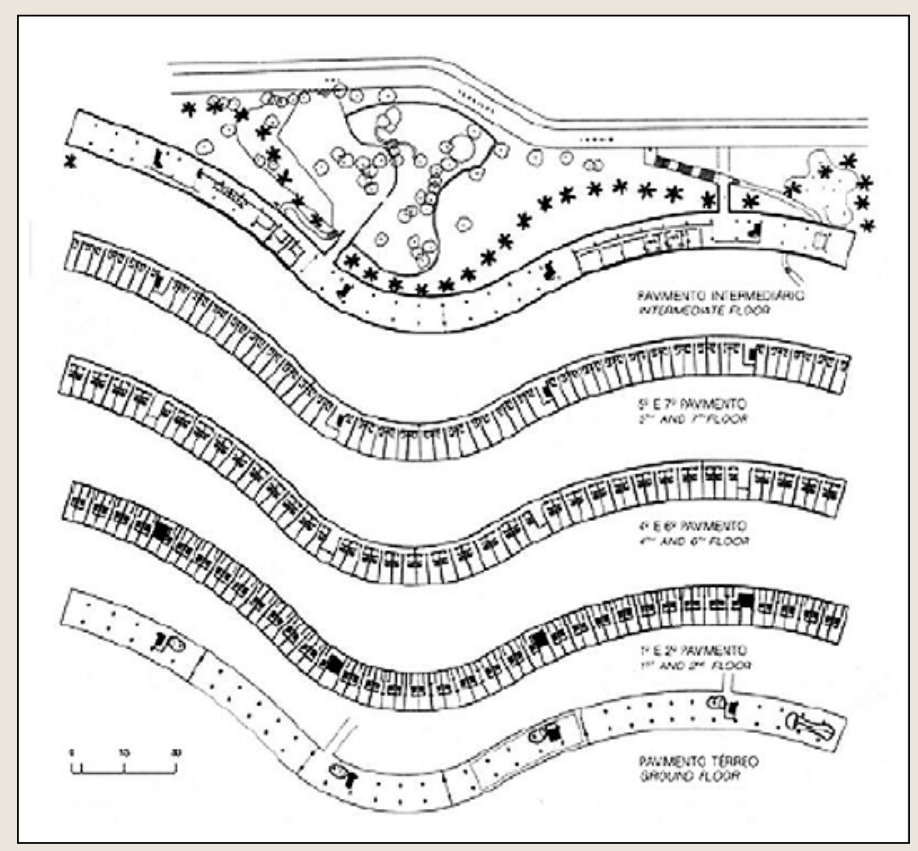

Figura 8. Pedregulho, planta bloque A. 
faldas de la colina (Fig. 9). El cuarto volumen no fue construido (Jovanovic y Von Fischer, 2002). Pedregulho también cuenta con una calle principal que recorre el perímetro del complejo para mantener las áreas verdes comunes libres de automóviles. Reidy, desconfiando de la capacidad de las autoridades de construir según lo proyectado, se aseguró de que lo que él consideraba la médula de los servicios comunes (guardería, escuela primaria, piscina, gimnasio, centro comercial y dispensario) fuesen construidos primero, ya que éstos no serían una prioridad una vez se hubiesen construido los bloques de vivienda.

Pedregulho tardó muchos años en completarse, tanto que para el momento en que las familias pudieron mudarse sus necesidades habían cambiado. La mayor parte de Pedregulho fue completada en los '50, incluyendo el bloque de viviendas que domina el conjunto. Fue el primer proyecto en

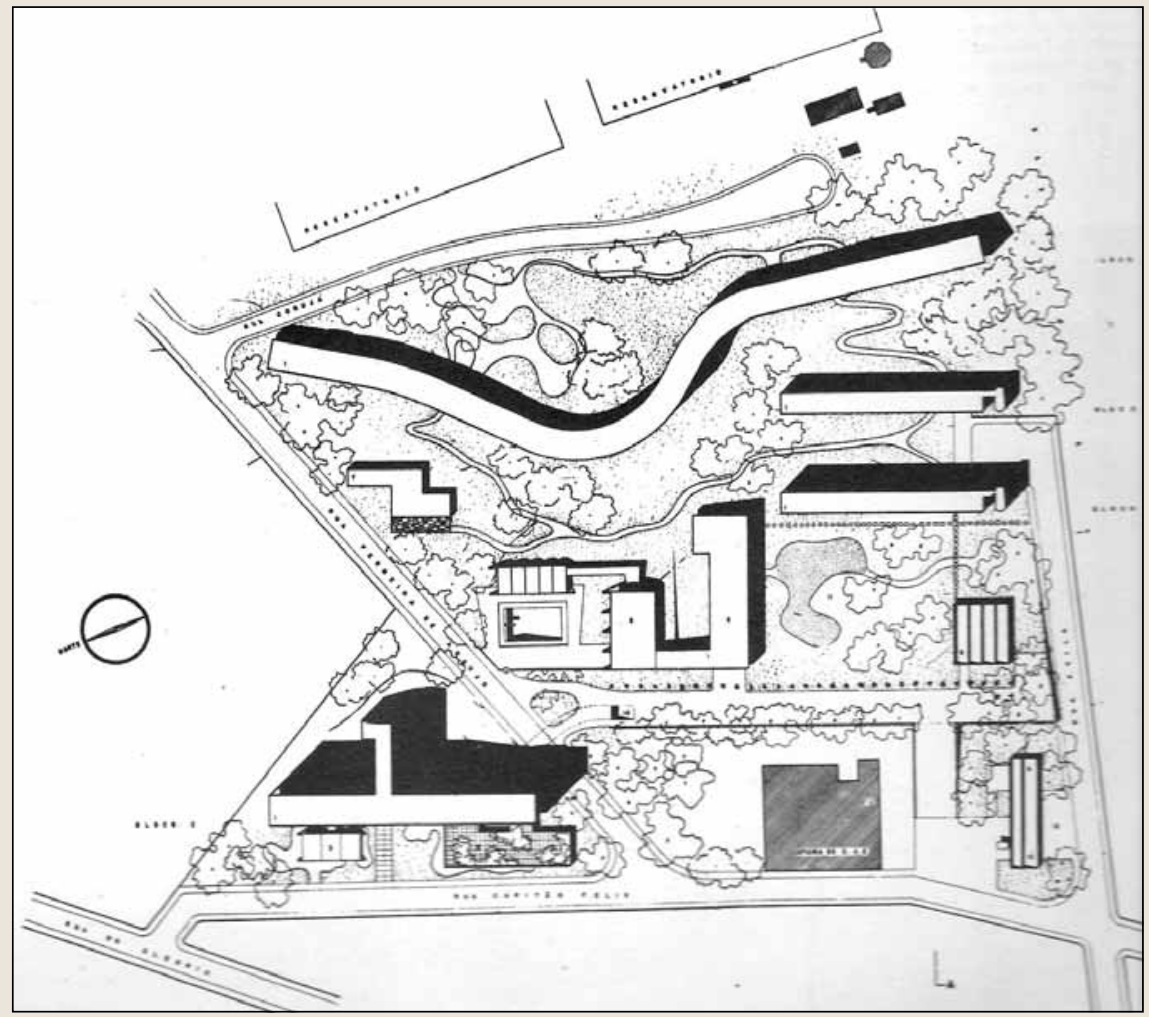

Figura 9. Pedregulho, plano conjunto, arquitectura contemporánea Brasil, revista Anteprojeto, Río de Janeiro 1947. 
contemplar estos tipos de servicios, y fue una inversión arriesgada de parte del gobierno populista de Getulio Vargas.

\section{DE LA MISERIA A LA MODERNIDAD: DISCIPLINA Y CONTROL PARA CIVILIZAR A LA CLASE OBRERA}

La arquitectura de Pedregulho es absolutamente moderna. Construido en las afueras de Río de Janeiro, en el distrito industrial de São Cristovão, la monumentalidad de Pedregulho es introvertida; el complejo de viviendas funciona como una comunidad autosuficiente y aislada del contexto urbano, contando con todo tipo de servicios para sus inquilinos. El proyecto fue muy alabado por críticos de arquitectura en Brasil y el mundo (entre ellos Walter Gropius); ganó el primer premio en la Primera Bienal de São Paulo en 1953 con un jurado presidido por el historiador y crítico de arquitectura y secretario perpetuo de los CIAM, Sigfried Giedion.

Pedregulho simboliza el rumbo de la modernización y la reforma social de Brasil, elevándose sobre la ciudad como un monumento de la futura nueva sociedad brasileña. Entre los criterios utilizados para seleccionar a los inquilinos, se requería su voluntad para someterse a "la estética pura y blanca de la arquitectura" (Jovanovic y Von Fischer, 2002). Como un "incentivo" para unirse a la administración municipal, era requisito para poder asegurarse un apartamento el trabajar para la municipalidad, deduciéndose la renta directamente del salario. Además, las familias que vendrían a conformar esta nueva sociedad debían ser chequeadas para descartar enfermedades contagiosas antes de poder mudarse al complejo, para no contaminar la pureza de la arquitectura y garantizar el éxito del proyecto de transformación social, ya que como afirmaba Le Corbusier "sin higiene ni salud moral, la célula social se atrofia” (2003, p. 63). En consecuencia, la necesidad del estricto control higiénico ejercido sobre los ocupantes del complejo habitacional.

El modelo de organización social al que eran sometidos los inquilinos de Pedregulho era fundamentalmente paternalista; éstos eran controlados por las autoridades bajo elaborados contratos de alquiler que incluían en sus cláusulas inspecciones periódicas a la propiedad por oficiales del Departamento de Habitación Popular (Fraser, 2000, p. 198). En concordancia con la aséptica y blanca estética moderna del conjunto arquitectónico, los inquilinos tenían el deber de mantenerse pulcros, a este fin se incluyó en el programa una lavandería comunal. Para incentivar su uso, la municipalidad obsequiaba a cada inquilino dos kilogramos anuales de detergente. Junto con la higiene física se controlaba la higiene moral, los trabajadores 
sociales se encargaban de verificar la veracidad de la información provista por cada inquilino, aquellos que mintieran o no cumplieran con las normas podían ser expulsados permanentemente de sus viviendas (Jovanovic y Von Fischer, 2002).

La relación de control y poder que se establece entre la administración pública de Río de Janeiro, Pedregulho y sus habitantes evoca el concepto de vigilancia derivado del Panopticón, modelo para una "casa de inspección" propuesta por el filósofo y reformista social inglés Jeremy Bentham a finales del siglo XVIII, momento en el cual el creciente desarrollo industrial británico produce no sólo una nueva clase proletaria urbana, sino también grupos de "desviados" que debían ser controlados y reformados. Tal y como se puede leer en el prefacio de su Panopticon Writings (Jeremy Bentham editado por Božovič, 1995, p. 31):

Morales reformadas - Salud preservada - industria revitalizada - instrucción difuminada - cargas públicas aligeradas- Economía basada, si así fuese, sobre una roca - el nudo Gordiano de las Leyes Pobres no están cortados, pero desamarrados - todo por una simple idea de Arquitectura! (traducción de Penélope Plaza)

La arquitectura del Panopticón se concibió como un edificio circular, donde las celdas de los prisioneros se disponían concéntricamente en el perímetro en torno a una torre de vigilancia ubicada en el centro (Fig. 10). La torre, a la que se accedía sin puertas ni entradas de luz, contaba con ventanas cubiertas por persianas con el fin de no delatar la presencia del carcelero. El concepto de esta "simple idea de arquitectura" es permitir que un único observador pueda observar/vigilar (-opticon) a todos (Pan-) los prisioneros sin que los mismos sean capaces de determinar si están siendo observados o no, creando una atmósfera de omnisciencia invisible. Esta omnisciencia funcionaría como instrumento para reformar a los prisioneros, quienes al sentirse permanentemente vigilados se verían forzados a reprimir sus comportamientos “desviados". Para el filósofo e historiador francés Michel Foucault, la prisión desde sus inicios estuvo "ligada a un proyecto de transformación de los individuos" (1978, p. 89), siendo un instrumento perfeccionado como la escuela o el cuartel que debía actuar con precisión científica.

Pedregulho no es un panóptico en el sentido literal arquitectónico, su estructura espacial no es "panóptica". Sin embargo, la manera como fue gestionado por la administración pública cabe dentro de lo que Foucault denominó como "panoptismo"; las instituciones que supervisaron el pro- 


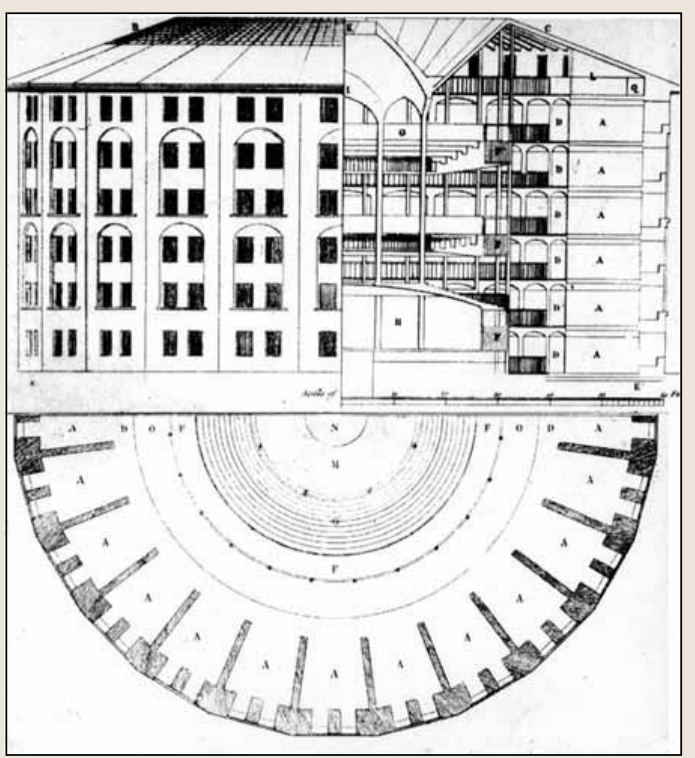

Figura 10. Panopticón, corte y planta. Bentham.

yecto funcionaron como "instituciones panópticas". El Panóptico, como lo define Foucault, debe ser "entendido como un modelo generalizable de funcionamiento; una manera de definir relaciones de poder en términos de la vida diaria de los hombres" (Foucault, 1993, p. 205). El Panóptico era también un laboratorio, podía ser utilizado como máquina para experimentos, para alterar comportamientos, entrenar o corregir individuos (Foucault, 1993, p. 203). En otras palabras, Pedregulho no fue concebido como Panóptico per se, pero la relación entre la arquitectura, sus habitantes y las autoridades (el poder) era "panóptica".

La arquitectura, en Pedregulho, era el vehículo para la "transformación social", para la transición de la miseria a la pureza, de la enfermedad a la salud, de la ignorancia a la educación, del rancho a la modernidad (Fraser, 2000, p. 197). Estos conceptos resuenan en las ideas del Movimiento Moderno, basadas en la convicción de que el hombre moderno del siglo XX necesitaba una nueva arquitectura, pero que esta nueva arquitectura a su vez era el vehículo para producir a un nuevo hombre y por lo tanto una nueva sociedad moderna.

$\mathrm{Al}$ introducir en la ciudad del presente la arquitectura moderna, la so- 
ciedad se vería forzada a reformarse bajo el carácter modernizador y civilizatorio impuesto por la arquitectura. Pedregulho es un proyecto emblemático de un período histórico en el que se creía que la nueva arquitectura era capaz de crear cambios sociales. Proyectos como éste debían ser modelos de la dirección que estaba tomando la transformación social en Brasil, y por extensión en Latinoamérica, y en consecuencia se requería un estricto control que garantizara que los ocupantes se comportaran de manera ejemplar. Sin embargo, este control necesario para garantizar la reforma social se vio imposibilitado por la complejidad logística inherente a la supervisión continua de todos los habitantes del complejo, así como por las sucesivas ocupaciones por diferentes inquilinos en décadas posteriores.

Tras su culminación, en 1958, los apartamentos en definitiva no fueron designados a las familias seleccionadas, y en el transcurso de los años los servicios comunales cambiaron su uso o fueron clausurados. El complejo fue abandonado a su suerte por la municipalidad, la indiferencia de la administración de la ciudad desencadenó el progresivo deterioro del conjunto (Pisani, 2010, p. 88). Al observar imágenes actuales del complejo (Fig. 6), podemos afirmar que el Complejo Habitacional Pedregulho no goza de buena salud. Las edificaciones presentan evidentes signos de "ranchificación", enfatizado por los altos índices de criminalidad que se reportan dentro del área, evidencia del fracaso del proyecto reformador. Pedregulho se eleva hoy en día sobre la ciudad de Río como el testimonio arquitectónico de un sueño moderno inconcluso.

\section{REFERENCIAS}

Bentham, Jeremy (1995). The Panopticon Writings. Editado por Miran Božovič. London: Yew Books.

Brace Taylor, Brian (1979). "Technology, Society and Social Control in Le Corbusier's Cité de Refuge, Paris”. Oppositions 15-16, 68-185.

Evenson, Norma (1973). Two Brazilian Capitals. New Haven: Yale University Press.

Frampton, Kenneth (1985). A Critical History of Modern Architecture. London: Thames and Hudson.

(1994). Modern Architecture: A Critical History. New York: Thames and Hudson.

Fraser, Valerie. 2000. Building a New World. Studies in the Modern Architecture of Latin America 1930-1960. London: Verso.

Foucault, Michel (1978). Microfísica del poder. Madrid: Las Ediciones de La Piqueta. 
. (1993). Vigilar y castigar: El nacimiento de la prisión. México: Siglo XXI ( 1 a edición en francés: 1984).

Guillén, Mauro (1997). "Scientific Management's Lost Aesthetic: Architecture, Organization, and the Taylorized Beauty of the Mechanical". Administrative Science Quarterly, Vol. 42, № 4, 682-715.

Jovanovic, S. y Von Fischer, S. (2002). "How to Read Two Monoliths", Cabinet Magazine, 6, primavera (edición electrónica).

Le Corbusier (2003). La ciudad del futuro. Buenos Aires: Ediciones Infinito (1 edición en francés: 1924).

McLeod, Mary (1983). “'Architecture or Revolution': Taylorism, Technocracy, and Social Change". Art Journal, Vol. 43, No. 2, Revising Modernist History: The Architecture of the 1920s and 1930s (Summer), 132-147.

Morse, Richard y Hardoy, Jorge (1992). Rethinking the Latin American City. Baltimore: Johns Hopkins University Press.

Mumford, Eric (2000). The CIAM discourse on Urbanism. Cambridge, Massachusets-London, MIT Press.

Pisani, Daniele (2010). "Il mondo de Pedregulho". Casabella, vol. 793, 78-97.

Violich, Francis (1944). Cities of Latin America: Housing and Planning to the South. New York: Reinhold.

Von Moos, Stanislaus (2009). Le Corbusier: Elements of a Sintesis. Rotterdam: 010 Publishers. 